\title{
WINDOWS BASED PROGRAM FOR WATER ESTIMATE OF VEGETABLES IN ARID AREAS
}

\author{
Abdulrahman, A. Alazba'; Abdullah, A. Alsadon ${ }^{2}$; Ibrahim, M. Alshahwan ${ }^{3}$;
}

Abdulrahman, S. Aldawood ${ }^{3}$ and Mohamad, B. El-Nesr ${ }^{1}$

1- Department of Agricultural Engineering, 2. Department of Plant Production, 3. Department of Plant Protection.

College of Food and Agricultural Sciences, King Saud University, P.O. Box 2460 Riyadh 11451 Saudi Arabia, alazba@ksu.edu.sa

Keywords: Vegetable crops, Water requirements, Developed computer program

\section{ABSTRACT}

A computer program based on windows application was developed using a Micro soft visual dot net software to determine the water requirements for vegetable crops in arid land. Through three simple steps, the user can easily calculate the water requirements for more than 35 vegetables. The first step is to locate the area of growing crops and compute the reference Evapotranspiration (ETref) using the Penman Monteith mathematical model. The second step is select the crop factor values and growing period lengths. Accordingly, the crop ET is calculated. The third step is to compute the total irrigation water requirements for the selected vegetable crop.

It is intended in the paper to show all mathematical background used in the calculations. In addition, snap shot screens will be used to illustrate the use of the developed computer program. 